\title{
TRENDS IN AUTHORITARIANISM: EVIDENCE FROM 31 EUROPEAN COUNTRIES
}

\section{Sabrina de Regt}

University of Antwerp

Master of Science in Sociology and Quantative Analysis in the Social Science

Sabrina.deRegt@ua.ac.be

\section{Tim Smits}

Catholic University of Leuven

Assistant Professor

Tim.Smits@soc.kuleuven.be

\section{Dimitri Mortelmans}

University of Antwerp

Associate Professor

Dimitri.Mortelmans@ua.ac.be

\begin{abstract}
-Abstract-
To date, few studies have been conducted on trends in authoritarian attitudes, despite the importance of this research in our understanding of undemocratic movements in society. Studies that have surveyed trends in authoritarianism are already rather outdated, often based on student samples and conducted in only a limited number of countries. Furthermore, until now, no study had tested whether the meaning of authoritarianism is invariant across time. Using the European Values Study, we examined trends in authoritarianism in 31 European countries over the last decade (1999-2008), based on representative samples. It was found that in many Western European countries, with the exception of the Netherlands, authoritarianism declined significantly over the last decade. However, in some, mostly Eastern European countries, levels of authoritarianism actually increased significantly during the last decade. Changing levels of authoritarianism were linked to extreme-right and anti-democratic sentiment in European societies.
\end{abstract}

Keywords: Authoritarianism, Measurement Invariance, European Values Study

JEL Classification: C38, O57, Z00 


\section{INTRODUCTION}

Several studies have already shown that authoritarian people vote for extreme right-wing parties (e.g. Meloen et al., 1999), and extreme right-wing parties throughout Europe have achieved great electoral successes during the last decade. Does this imply a general increase in authoritarian attitudes in European countries? At the same time, however, we see that Eastern European countries have become more democratic over the last decade. Has the transition to democracy lowered the authoritarian scores in those countries?

Previous studies provide much information on the correlates of authoritarianism, but less is known about changes in authoritarianism over time. Trend studies are important, however, in order to understand the concept of authoritarianism more deeply, since reported correlates are strongly rooted in historical moments and political change. In this study we will examine trends in authoritarianism in 31 European countries during the last decade, based on representative samples.

\section{EXISTING TIME SERIES ANALYSES OF AUTHORITARIANISM}

The majority of existing studies on trends in authoritarianism were conducted in the United States, and show that changes in American society and culture seem to be accompanied by changes in authoritarianism scores. Freedman (1961) reported very high scores in 1904, while the lowest scores were found in the 1930s and 1940s. Authoritarianism levels in the 1950s were higher than those found in the late 1960s and the 1970s (Meloen, 1998; Ondrack, 1976; Whitten, 1976).

Only a small number of studies on trends in authoritarian attitudes have been conducted outside the United States. Altemeyer (1981) examined cross-sectional changes of authoritarian item scores in Canada between 1973 and 1979 and found a slow but steady upward trend for most items. This climb in student authoritarianism scores continued during the 1980s (Altemeyer, 1988) but, following a steady rise between 1973 and 1987, scores declined gradually (Altemeyer, 1996). Meloen and Middendorp (1999; 1991) studied authoritarianism in the Netherlands based on representative samples in 1970, 1975, 1980, 1985 and 1992, and reported a clear trend towards lower authoritarianism scores throughout this period.

Many studies have been conducted within a single country. A notable exception is Lederer (1982), who reported on changes in the authoritarian attitudes of adolescents over a 33-year period in West Germany and in the United States. In both the United States and West Germany a significant decrease in authoritarianism was noted, with a larger decrease in West Germany. In the period 
immediately following the Second World War, German adolescents were more authoritarian than adolescents in the United States. By the end of the 1970s, however, the reverse was true.

This paper aims to expand on existing knowledge relating to four points. First, we will examine trends in authoritarianism in 31 countries from across Europe. Previous studies provide an interesting picture of cross-sectional trends in authoritarianism, but information is available for only a small number of countries (four). While increasing levels of authoritarianism were found in Canada in the 1970s (Altemeyer, 1981), authoritarianism scores seem to have decreased in the Netherlands in the same period (Meloen, 1999; Meloen and Middendorp, 1991). This demonstrates the importance of examining multiple socio-political contexts in order to obtain a clearer picture. Second, we will test whether the structure and interpretation of authoritarianism has changed over time. Altemeyer (1981) reported that the consistency of answers to authoritarian items went down dramatically. The drop in mean inter-item correlations was significant, and shows that it is essential to study the stability of the construct before comparing authoritarianism means across time. Third, many previous studies were conducted some time ago and recent changes in society (e.g. increasing support for extreme right-wing parties) make it interesting to test whether levels of authoritarianism have increased or decreased more recently. Fourth, many studies were based exclusively upon student samples and we do not know whether these results are representative of the whole population. In this paper, we will examine the trend in authoritarianism scores based on representative samples. Finally, we will link the trends in authoritarianism with anti-democratic and extreme-right sentiment in European societies.

\section{MEASUREMENT EQUIVALENCE}

When scores on an instrument cannot be interpreted in the same way in different contexts (e.g. different countries or time periods) and thus do not have the same psychological meaning, they are referred to as inequivalent. When comparing scores obtained with inequivalent measurements, we might draw suboptimal or even incorrect conclusions, and it is therefore essential to explicitly test for invariance before applying a measurement in different contexts (Van de Vijver and Poortinga, 1997). Measurement equivalence can be considered a hierarchical concept. The first level of invariance is configural invariance. It requires that the same items load on the latent construct (i.e. authoritarianism) in both contexts. Metric invariance, a higher level of invariance, requires that the factor loadings are identical across differing situations. A more strict level of invariance is scalar 
invariance. Besides identical factor loadings, equal intercepts are also required for this level of measurement invariance and only when this level of invariance is fulfilled can we meaningfully compare means across situations.

\section{DATA, MEASUREMENTS AND METHODS}

\subsection{Data}

To examine trends in authoritarianism over the last decade, we will use the third (1999) and fourth (2008) waves of the European Values Study (EVS). We focus on the two most recent waves of the EVS in order to maximize the number of countries available for study. The EVS provides information on a wide range of values held by citizens throughout Europe. Face-to-face interviews were conducted among representative samples of people aged 18 and older. Detailed information on sampling, weighting, fieldwork procedures, translation and the questionnaire in general can be found at www.europeanvaluesstudy.eu. In this study, data from 31 countries included in both waves will be examined. A list of these countries and the corresponding sample sizes can be found in Table 1.

\subsection{Measurement}

The following nine items are used to measure authoritarianism: whether homosexuality, abortion, divorce, euthanasia and having casual sex are acceptable; whether people prefer a strong leader who does not have to bother with parliaments and elections; whether obedience is an important quality children should learn at home; whether one should always love and respects one's parents regardless of their qualities and faults; and whether people believe that greater respect for authority in the future is a good thing. See de Regt et al. (2010) for more information on the validation of this scale.

\subsection{Methods}

We used cross-time multiple-group confirmatory factor analysis (MGFCA: Jöreskog, 1971) to test for invariance and to examine changes in authoritarianism means over the last decade. The mean vector, covariance matrix and asymptotic covariance matrix were estimated under equal thresholds. Maximum likelihood was employed as an estimation method. The Expectation-Maximization algorithm (Dempster, Laird, \& Rubin, 1977) was used to impute missing values within a scale (mean percentage missing values was 5.70 for 1999 and 6.02 for 2008).

\section{RESULTS}

In this section, we test the cross-time scalar invariance of authoritarianism. As a prerequisite, it is customary first to estimate the measurement model separately in 
each group (Byrne, 2001), and to test for configural and metric invariance. Due to limits of space, these models are not displayed here but are available from the authors on request. The results of estimating the scalar equivalence models (i.e. identical factor loadings and item intercepts) are shown in Table 1. In this table the $d f$, the $\chi^{2}$, the RMSEA and CFI are shown. Because of the known sensitivity of $\chi^{2}$ statistics to sample size (Byrne, 2001), we do not use this test statistic to evaluate our models. RMSEA values of less than 0.05 are often considered to indicate a good fit of the model with the observed data, and values of upto 0.08 represent reasonable errors of approximation in the population (Browne and Cudeck, 1993). The CFI can range from 0 to 1 and a value of 0.90 and above indicates a satisfactory fit of the model with the data (Bentler, 1992). In the majority of countries, as reported in Table 1, the strictest invariance model complies with the fit indices (RMSEA $<0.08$ and CFI $>0.90$ ). This implies that in 2008, people understood authoritarianism in the same way that people understood it in 1999, and that we can meaningfully compare authoritarianism levels across time.

Small modifications were needed for some countries in order to achieve a reasonable fit of the model (for example, allowing errors relating to 'respect for parents' and 'teach children obedience at home' to correlate, because both concern family relations). No more than two correlations between error terms were allowed. In some countries the assumption of identical intercepts has been relaxed for one, or at most two items. In Hungary and Romania, for example, the assumption of equal intercepts for the 'accept homosexuality' variable has been relaxed. Hungary recently recognised registered partnerships for same-sex couples, and a 2006 campaign calling for the legalisation of same-sex unions in Romania resulted in widespread debate in the media on this theme. These national events justify the relaxation of the assumption of equal intercepts for this issue. 
INTERNATIONAL JOURNAL OF SOCIAL SCIENCES AND HUMANITY STUDIES

Vol 3, No 1, 2011 ISSN: 1309-8063 (Online)

Table 1. Global Fit Cross-Time Scalar Equivalence Authoritarianism

\begin{tabular}{|c|c|c|c|c|c|c|c|c|}
\hline Country & n 1999 & n 2008 & $d f$ & $\chi^{2}$ & RMSEA & $\mathrm{CI}^{\mathrm{a}} \mathrm{RMSEA}$ & CFI & $\begin{array}{l}\Delta \text { Mean AUT } \\
2008 \text { vs. } 1999\end{array}$ \\
\hline Austria $^{b}$ & 1355 & 1363 & 68 & 964.96 & 0.069 & $0.064-0.075$ & 0.96 & $-0.41 * *$ \\
\hline Belarus $^{c}$ & 960 & 1163 & 68 & 833.51 & 0.071 & $0.065-0.071$ & 0.92 & $0.96 * * *$ \\
\hline Belgium & 1843 & 1487 & 70 & 956.29 & 0.066 & $0.061-0.071$ & 0.94 & $-0.70 * * *$ \\
\hline Bulgaria & 973 & 1163 & 70 & 705.93 & 0.060 & 0.054-0.066 & 0.95 & $0.21 *$ \\
\hline Czech & 1908 & 1441 & 70 & 1127.40 & 0.072 & $0.067-0.077$ & 0.94 & $0.34 * * *$ \\
\hline Denmark & 918 & 1393 & 70 & 882.30 & 0.069 & $0.063-0.075$ & 0.95 & $-0.45 * *$ \\
\hline Estonia & 920 & 1321 & 70 & 651.26 & 0.063 & $0.057-0.070$ & 0.94 & $0.30 * *$ \\
\hline Finland $^{\mathrm{bc}}$ & 976 & 823 & 67 & 569.78 & 0.069 & $0.062-0.076$ & 0.95 & $-1.09 * * *$ \\
\hline France $^{b}$ & 1552 & 1472 & 68 & 883.73 & 0.067 & $0.062-0.073$ & 0.96 & $-0.44 * *$ \\
\hline Germany $^{\text {b }}$ & 1888 & 1781 & 68 & 1335.39 & 0.072 & $0.068-0.077$ & 0.95 & $-0.33 * *$ \\
\hline Great Britain & 905 & 1434 & 70 & 520.66 & 0.054 & $0.048-0.060$ & 0.97 & $-0.24 *$ \\
\hline Greece $^{c}$ & 1094 & 1422 & 68 & 884.88 & 0.067 & $0.061-0.073$ & 0.95 & $1.01 * * *$ \\
\hline Hungary $^{c}$ & 979 & 1459 & 69 & 774.03 & 0.063 & $0.057-0.069$ & 0.95 & $-1.48 * * *$ \\
\hline Iceland & 944 & 747 & 70 & 454.81 & 0.052 & $0.045-0.060$ & 0.96 & $-0.92 * * *$ \\
\hline Ireland & 955 & 787 & 70 & 651.06 & 0.067 & $0.060-0.074$ & 0.96 & $-1.14 * * *$ \\
\hline Italy & 1929 & 1318 & 70 & 1059.12 & 0.064 & $0.059-0.069$ & 0.97 & $0.58 * * *$ \\
\hline Latvia $^{b}$ & 950 & 1162 & 69 & 662.82 & 0.065 & $0.059-0.071$ & 0.93 & $-0.83 * * *$ \\
\hline Lithuania & 965 & 1124 & 70 & 661.86 & 0.062 & $0.056-0.069$ & 0.94 & $-0.52 * * *$ \\
\hline Luxembourg & 1127 & 1465 & 70 & 708.30 & 0.064 & $0.058-0.070$ & 0.96 & $-0.46^{* * *}$ \\
\hline Malta $^{c}$ & 998 & 1285 & 69 & 2168.59 & 0.070 & $0.064-0.076$ & 0.95 & $-1.52 * * *$ \\
\hline Netherlands & 992 & 1472 & 70 & 710.54 & 0.063 & $0.057-0.069$ & 0.98 & $0.43 * * *$ \\
\hline Poland & 1063 & 1350 & 70 & 929.30 & 0.070 & $0.064-0.076$ & 0.96 & $-0.37 * *$ \\
\hline Portugal $^{\mathrm{b}}$ & 975 & 1508 & 68 & 908.61 & 0.071 & $0.065-0.077$ & 0.94 & $-0.37 * * *$ \\
\hline Romania $^{b c}$ & 1109 & 1229 & 67 & 1070.32 & 0.071 & $0.065-0.078$ & 0.93 & $-0.32 * *$ \\
\hline Russia & 2424 & 1209 & 70 & 938.67 & 0.059 & $0.054-0.063$ & 0.92 & $0.22 * *$ \\
\hline Slovakia & 1259 & 1123 & 70 & 792.23 & 0.067 & $0.061-0.073$ & 0.96 & $0.41 * * *$ \\
\hline Slovenia ${ }^{b}$ & 955 & 1227 & 69 & 793.20 & 0.069 & $0.063-0.075$ & 0.95 & $0.46^{* *}$ \\
\hline Spain & 1132 & 1375 & 70 & 995.44 & 0.071 & $0.065-0.077$ & 0.97 & $-0.91 * * *$ \\
\hline Sweden $^{\mathrm{b}}$ & 960 & 820 & 65 & 811.51 & 0.072 & $0.065-0.080$ & 0.96 & $-1.13 * * *$ \\
\hline Turkey & 1188 & 2032 & 70 & 1782.28 & 0.070 & $0.065-0.070$ & 0.95 & $0.75 * * *$ \\
\hline Ukraine & 1145 & 1134 & 70 & 684.00 & 0.056 & $0.049-0.062$ & 0.95 & $0.58 * * *$ \\
\hline
\end{tabular}


Figure-1: Authoritarianism Trends in Europe

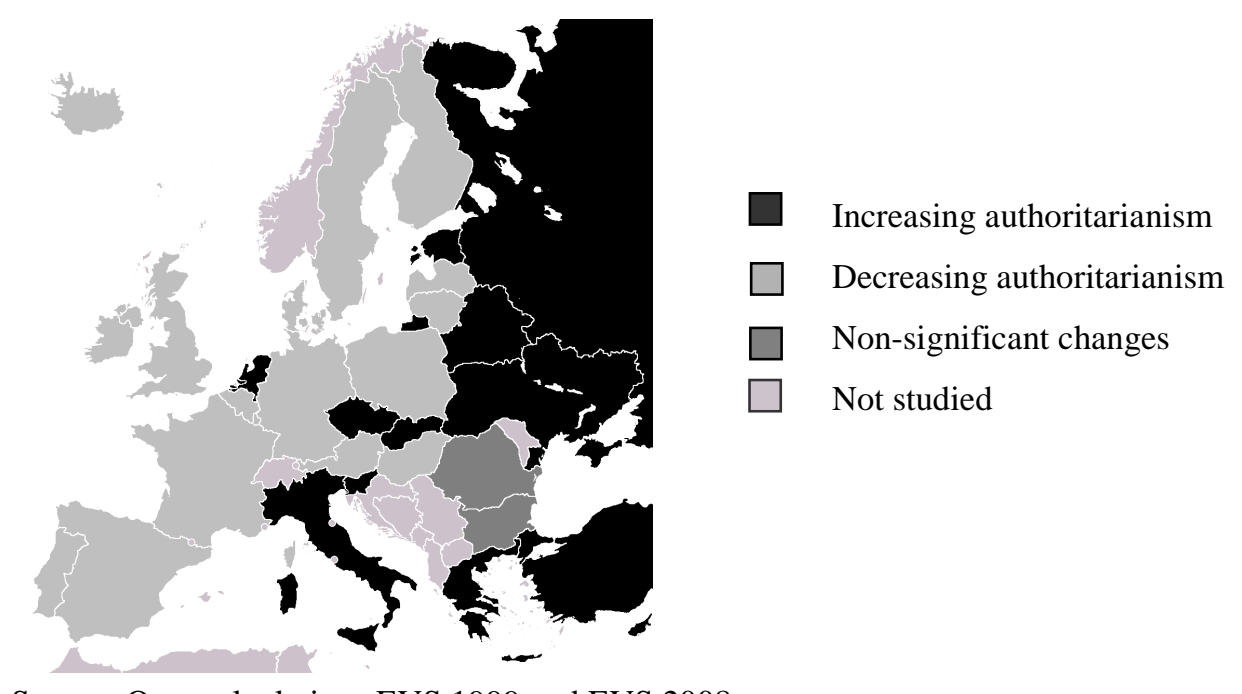

Source: Own calculations EVS 1999 and EVS 2008

The data in the final columns of Table 1 reveal that in 18 European countries the levels of authoritarianism have decreased over the last decade, while in 11 countries the levels of authoritarianism have actually increased significantly. With the large sample sizes used in this study, the changes in Bulgaria and Romania can be considered insignificant. If we examine the changes in authoritarianism (displayed in Figure 1) in more detail, we find that in many Western European countries (e.g. Belgium, France, Germany and Luxembourg) and Scandinavian countries (e.g. Denmark, Finland and Sweden) people have become significantly less authoritarian during the last decade. Countries where people have become significantly more authoritarian are mostly Eastern European countries (e.g. Belarus, Ukraine and Russia).

\section{ASSOCIATED SOCIETAL TRENDS}

Next we examine whether these trends in authoritarianism are associated with trends in anti-democratic and extreme-right sentiment in society. As part of the EVS, respondents were asked to position their views on a political scale from left (1) to right (10). We find that $7.9 \%$ of the population in countries with declining authoritarianism scores place themselves in the most extreme-right position (9 and 10 ), while $9.28 \%$ of the population in countries with increasing authoritarianism levels position themselves to the extreme right of the political self-positioning scale. Because of the limited number of observations $(n=31)$, however, this difference is not statistically significant $(p=.36)$. 
In order to test whether trends in authoritarianism can be linked to anti-democratic movements, we make use of the EVS question on whether having a democratic political system is a good way of governing a country $(1=$ very good $-4=$ very bad). Results show that in countries where authoritarianism scores have risen, people feel on average more negatively about having a democratic political system (mean $=1.67$ for countries with decreasing authoritarianism levels and 1.81 for countries with increasing authoritarianism sentiments, $p=0.12$ ). Because of the limited number of countries available, these differences are only indicative and not statistically significant. Though high levels of extreme-right and antidemocratic sentiment in society seem to be linked to increasing authoritarianism levels, the change in authoritarianism is unrelated to the change in anti-democratic attitudes and extreme-right self-positioning (respectively $r=0.08, p=0.68$ and $r$ $=0.05, p=0.80)$.

\section{CONCLUSION}

Few cross-time studies on authoritarianism are currently available. Studies that have examined the issue have become outdated, are often based on student samples and study only a limited number of countries. Furthermore, no earlier study on authoritarianism had tested whether the authoritarianism scale was measurement invariant over time. In this article, we examined trends in authoritarian attitudes in 31 European countries over the last decade, based on representative samples, using appropriate statistical methods. We found that it is statistically justifiable to compare authoritarianism scores from 1999 with those found in 2008. Decreasing levels of authoritarianism were found in Western European countries in particular. In some Eastern European countries, however, levels of authoritarianism increased significantly. We observed that it is important to gain deeper insight into cross-time changes in authoritarianism, as increasing levels of authoritarianism seem to be associated with higher levels of antidemocratic and extreme-right movements in society.

\section{BIBLIOGRAPHY}

Altemeyer, B., 1981. Right-wing authoritarianism. University of Manitoba Press, Winnipeg.

Altemeyer, B., 1988. Enemies of freedom: Understanding right-wing authoritarianism. Jossey-Bass, San Francisco.

Altemeyer, B., 1996. The authoritarian spectre. Harvard University Press, Cambridge. 
Bentler, P.M., 1992. On the fit of models to covariances and methodology to the Bulletin. Psychological Bulletin 112, 400-404.

Browne, M.W., Cudeck, R., 1993. Alternative ways of assessing model fit., In: Bollen, K.A., Long, J.S. (Eds.), Testing structural equation models. Sage, Newbury Park, pp. 445-455.

Byrne, B.M., 2001. Structural equation modeling with AMOS: Basic concepts, applications, and programming Lawrence Erlbaum, Mahwah, NJ.

de Regt, S., Smits, T., Mortelmans, D., 2010. On cross-national variation in the correlation between authoritarianism and social dominance orientation. Politics, Culture and Socialization 1, 311-322.

Freedman, M.B., 1961. Changes in six decades of some attitudes and values held by educated women. Journal of Social Issues 17, 19-28.

Jöreskog, K.G., 1971. Simultaneous factor analysis in several populations. Psychometrika 36, 409-426.

Lederer, G., 1982. Trends in authoritarianism: A study of adolescents in West Germany and the United States since 1945. J. Cross-Cult. Psychol. 13, 299-314.

Meloen, J., 1998. Fluctuations of authoritarianism in society: an empirical time series analysis for the dynamic socio-political and economic influence on authoritarianism in American society, 1954-1977. Social Thought \& Research 21, 107-132.

Meloen, J., 1999. Authoritarianism in The Netherlands : Mission completed? Downward trends in authoritarianism in The Netherlands 1970-1992 with an international comparison of world data. Social Thought \& Research 22, 45-93.

Meloen, J., de Witte, H., van der Linden, G., 1999. Authoritarianism and voting for a racist party in Belgian Flanders: A model tested among secondary school pupils. Politics, Groups and the Individual 8.

Meloen, J., Middendorp, C., 1991. Authoritarianism in the Netherlands: The empirical distribution in the population and its relation to theories on authoritarianism 1970-1985. Politics and the Individual 1, 49-72.

Ondrack, D.A., 1976. Time-series analysis of dogmatism norms among college students. Journal of Applied Social Psychology 6, 134-144. 
Van de Vijver, F.J.R., Poortinga, Y.H., 1997. Towards an integrated analysis of bias in cross-cultural assessment. European Journal of Personality Assessment 13, 29-37.

Whitten, N.E., 1976. Authoritarian personalities, 1950-1973. Journal of Personality Assessment 40, 622-625. 